\title{
Additional Positive Electric Residues in the Crucial Spike Glycoprotein S Regions of the New SARS-CoV-2 Variants
}

\section{Piotr H Pawłowski (iD}

Institute of Biochemistry and Biophysics, Polish Academy of Sciences, Warszawa, Poland
Correspondence: Piotr H Pawłowski Tel +48-22-659-70-72

Email piotrp@ibb.waw.pl

\begin{abstract}
The change in the formal charge of 34 SARS-CoV-2 lineages from September 2020 to June 2021 was analyzed according to the monthly evidence of the European agency. The reported point mutations and small insertions are electrically neutral (17), positive (12), or negative (3). They had been found in the spike glycoprotein $\mathrm{S}$, in the RBD and $\mathrm{S} 1 / \mathrm{S} 2$ regions, crucial for initiation of viral infection. The most often observed were positive mutations, especially D614G and E484K, located in the region of S1/S2 junction, and in the receptorbinding domain (RBD), respectively. They are related to $\mathrm{G}$ and A switching. Positive mutations are stretching equally in both areas, but in the RBD region, they are more dispersed. In the set of analyzed virus variants, the increasing tendency in the number of positively charged residues in spike protein was observed. Furthermore, the well-documented WHO classes show an increase in the COVID-19 percentage case fatality with the positive increase in the spike crucial region's total charge. The data mining, applying classifier algorithm based on the artificial neuronal network, confirms that the value and the distribution of additional positive charge in S may be important factors enabling virus impact to immunity. This may be promoted by the stronger longrange electrostatic attraction of the virus particle to the host cell, preceding the infection. The estimation of the potential energy for the RBD approaching the angiotensin-converting enzyme (ACE2) was presented.
\end{abstract}

Keywords: coronavirus, COVID-19, SARS-CoV-2, spike protein S, amino acids, charge, potential energy, electrostatic interactions

\section{Introduction}

It was recently discussed the role of the net positive electric charge in the influenza A virus binding to, or released from the infected, host cell, ${ }^{1,2}$ and the possible anionic prevention. ${ }^{3}$ Similarly, electrical features of the structure of COVID-19 coronavirus have aroused interest since the beginning of the pandemic. ${ }^{4}$ An adequate concept was presented that special distributions of charged amino acids (Figure 1) can, in an electrostatic manner, facilitate both the SARS-CoV-2 infection of the cells and the interaction with potential drugs. ${ }^{5}$ In the area of biochemical research, the electrostatic inhibition of interplaying furin ${ }^{6}$ and the electrostatic interactions of therapeutic antibodies with RBD was considered. ${ }^{7}$ In the field of practical applications, the physical basis of electrostatic filter prevention was discussed. $^{8}$

This manuscript is a continuation of the previous paper. ${ }^{5}$ Current work examines the number of positive charges in the spike proteins of SARS-CoV-2 and concludes 


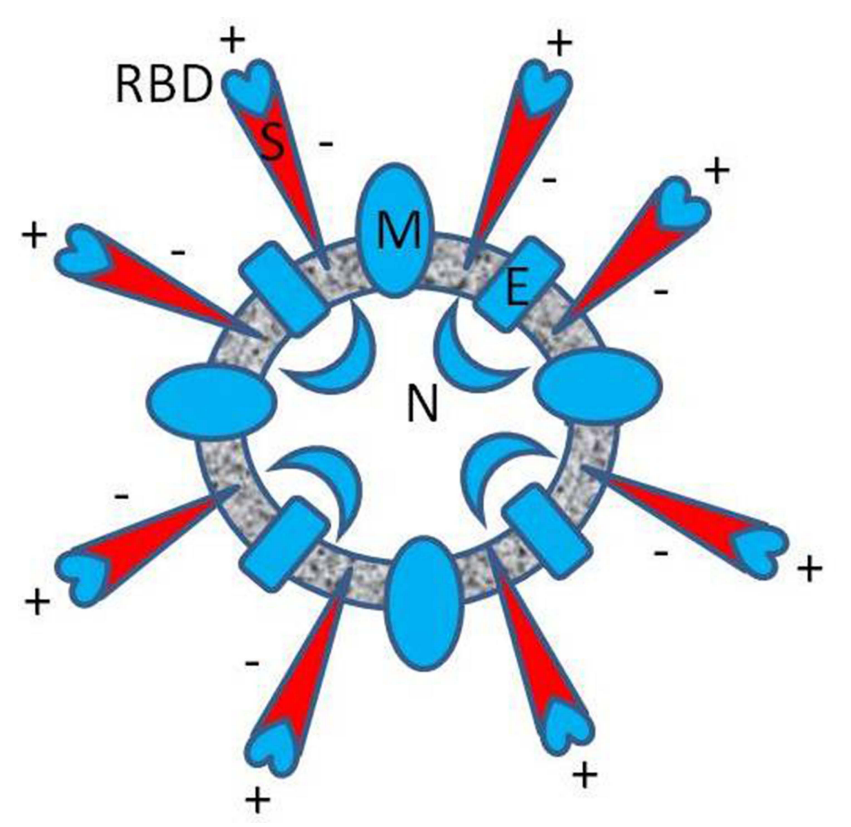

Figure I Approximate diagram of the spatial distribution of electric charge in SARS-CoV-2 (B.I variant). The resultant formal charge, estimated from the charged amino acid content of the envelope (E), the membrane (M), and the nucleocapsid protein $(\mathbf{N})$ is positive (blue), respectively 2, 8, 24 elementary charge units [e]. The entire charge of spike protein $(\mathbf{S})$ is negative (red), -12 [e], but locally, in the RBD, the resultant charge is positive, +7 [e], as was reported in Pawłowski's study. ${ }^{5}$

that systematically new coronavirus variants have more positive charges in them. The importance of the consequences of this phenomenon is emphasized.

How it was recently postulated, the long-range electrostatic interactions of positive and negative charges of RBD and ACE2, respectively, and the short-range interactions of the dipoles tangent to the border of contacting molecular surfaces can make it much easier for a virus to reach and bind to the cell. ${ }^{9}$ The evidence of the European Centre for Disease Prevention and Control (ECDC) on SARSCoV-2 variants detected as of 8th July $2021^{10}$ shows a systematic increase of positive charge in RBD and $\mathrm{S} 1 /$ $\mathrm{S} 2$ cleavage areas of $\mathrm{S}$ protein in successive monthly reported new lineages (Figure 2). The 32 mutations repeated in 34 new lineages are indicated in Table 1, with the protein $\mathrm{S}$ region, the number of cases, the change of the formal charge, and the time of first detection. The positive formal charge in mutations (72) dominates over the neutral (43) and the negative (11) ones (Figure 3). The number of positive cases in the RBD region is the same as for the S1/S2 cleavage area.

According to the data published by Public Health England (PHE), ${ }^{11}$ the COVID-19 percentage case fatality increases with the formal charge increase in discussing areas of S protein of new investigated variants (Figure 4).

\section{Materials and Methods Neuronal Analysis of S Charge Impact on Immunity}

To determine how much the additional charge of spike protein determines the impact of SARS-CoV-2 variants on immunity, the classification process with the use of three machine learning classification algorithms in Weka 3.8.5 was carried out. There were deep learning

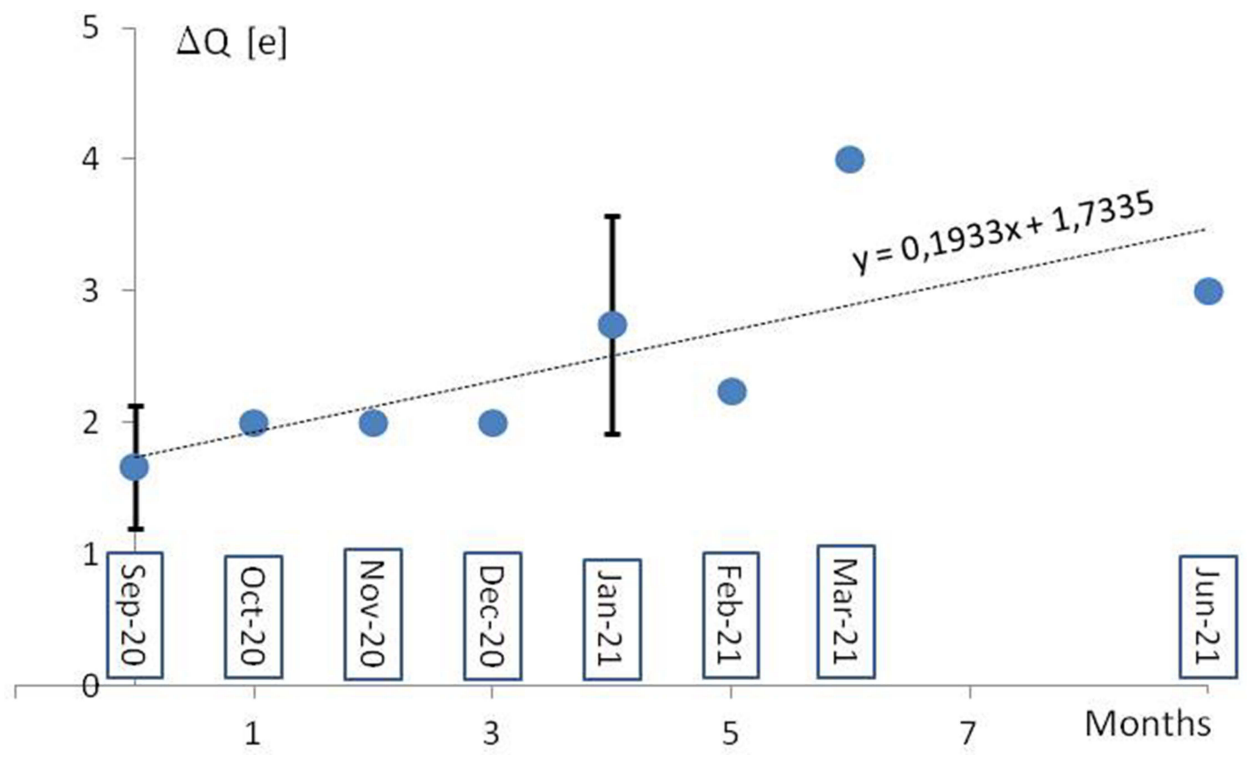

Figure 2 A mean increase of formal electric charge in RBD and SI/S2 cleavage regions in the lineages monthly reported by ECDC from September 2020 to June 202I. The formal charge means the charge of the amino acids at neutral $\mathrm{pH}$, in elementary charge units. The reference "wild-type"' virus B.I was assumed (with no mutation D6I4G and other spike protein changes). The standard deviation of the population (vertical bar) was shown. 
Table I Mutations in SARS-CoV-2 Variants of Concern as of 8 July 202I (ECDC Report) the Data in Columns Were Collected for All Reported Lineages and Their Mutations. Many Mutations Occur in Several Lineages

\begin{tabular}{|c|c|c|c|c|}
\hline Region & Mutation & $\begin{array}{c}\text { Number of } \\
\text { Cases } \\
\text { (Modified } \\
\text { Lineages) }\end{array}$ & $\begin{array}{c}\text { Change of } \\
\text { Formal } \\
\text { Charge } \Delta Q \\
{[\mathrm{e}]}\end{array}$ & $\begin{array}{l}\text { Time of } \\
\text { First } \\
\text { Detection }\end{array}$ \\
\hline $\begin{array}{l}\mathrm{N} \text {-terminal } \\
\text { domain }\end{array}$ & ins214TDR & 1 & 0 & Dec-20 \\
\hline RBD & $\begin{array}{l}\text { R346K } \\
\text { V367F } \\
\text { P384L } \\
\text { Q4I4K } \\
\text { K4I7N } \\
\text { K4I7T } \\
\text { N439K } \\
\text { N450K } \\
\text { L452Q } \\
\text { L452R } \\
\text { S477N } \\
\text { T478K } \\
\text { V483A } \\
\text { E484K } \\
\text { E484Q } \\
\text { F490S } \\
\text { S494P } \\
\text { N50IT } \\
\text { N50IY } \\
\text { E5I6Q }\end{array}$ & $\begin{array}{c}1 \\
1 \\
1 \\
1 \\
4 \\
2 \\
1 \\
1 \\
1 \\
10 \\
2 \\
3 \\
1 \\
16 \\
2 \\
2 \\
1 \\
1 \\
12 \\
1\end{array}$ & $\begin{array}{c}0 \\
0 \\
0 \\
1 \\
-1 \\
-1 \\
1 \\
1 \\
0 \\
1 \\
0 \\
1 \\
1 \\
2 \\
1 \\
0 \\
0 \\
0 \\
0 \\
1\end{array}$ & $\begin{array}{l}\text { Jan-2l } \\
\text { Dec-20 } \\
\text { Dec-20 } \\
\text { Dec-20 } \\
\text { Sep-20 } \\
\text { Dec-20 } \\
\text { Mar-21 } \\
\text { Dec-20 } \\
\text { Dec-20 } \\
\text { Sep-20 } \\
\text { Dec-20 } \\
\text { Nov-20 } \\
\text { Feb-21 } \\
\text { Sep-20 } \\
\text { Dec-20 } \\
\text { Dec-20 } \\
\text { Jan-21 } \\
\text { Dec-20 } \\
\text { Sep-20 } \\
\text { Jan-21 }\end{array}$ \\
\hline $\begin{array}{l}\text { SI/S2 } \\
\text { junction }\end{array}$ & $\begin{array}{c}\text { Q613H } \\
\text { D6I4G } \\
\text { A653V } \\
\text { H655Y } \\
\text { G669S } \\
\text { Q677H } \\
\text { ins679GIAL } \\
\text { N679K } \\
\text { P68IH } \\
\text { P68IR } \\
\text { A70IV }\end{array}$ & $\begin{array}{c}1 \\
31 \\
1 \\
5 \\
1 \\
2 \\
1 \\
1 \\
10 \\
4 \\
4\end{array}$ & $\begin{array}{c}0 \\
1 \\
0 \\
-1 \\
0 \\
0 \\
0 \\
1 \\
0 \\
1 \\
0\end{array}$ & $\begin{array}{l}\text { Dec-20 } \\
\text { Sep-20 } \\
\text { Dec-20 } \\
\text { Dec-20 } \\
\text { Feb-21 } \\
\text { Dec-20 } \\
\text { Jan-21 } \\
\text { Jan-21 } \\
\text { Sep-20 } \\
\text { Dec-20 } \\
\text { Sep-20 }\end{array}$ \\
\hline
\end{tabular}

D14jMlpClassifier, Logistic regression model, and the neuronal network algorithm, MultilayerPerceptron. The 28 well-documented lineages (instances) with the clear evidence for some impact on immunity, described by 37 attributes (32 possible mutations, characterized by the occurrence nominal labels $\{1,0\}$, and 4 numeric parameters: the time (month) of the first detection, the total change of charge in $\mathrm{S}$, the charge change in RBD, and the charge change in the S1/S2 cleavage area, followed by the class decision attribute with the nominal labels \{no, neutralization, escape\}) were used to develop the classification model, relating classes of the evidence for impact on immunity to the other attributes of virus lineages. ${ }^{10}$

The final model offering the best classification of instances (conceptual visualization in Figure 5) was the neuronal network obtained with the MultilayerPerceptron classifier (weka.classifiers.functions.MultilayerPerceptron -L 0.3 -M 0.2 -N 5000 -V 0 -S 0 -E 20 -H a -R). ${ }^{12}$ In this case, the weights for the inputs of each attribute to a given neuronal node and the threshold for the sigmoid transfer function were fitted.

\section{Calculation of the Potential Electrostatic Screened Energy}

The potential electrostatic screened energy $U$ was estimated for charged RBD and ACE2 as a function of a distance d. Point model and screened Coulomb energy formula $\mathrm{U}=\mathrm{Q}_{1} \mathrm{Q}_{2} \operatorname{Exp}\left(-\mathrm{d} / \mathrm{L}_{\mathrm{D}}\right) /\left(4 \Pi \varepsilon_{0} \varepsilon \mathrm{d}\right)$ was assumed, with $\mathrm{Q}_{1}=+7[\mathrm{e}]$ or $\mathrm{Q}_{1}=+10[\mathrm{e}], \mathrm{Q}_{2}=-28[\mathrm{e}], \varepsilon=80$, and Debye screening length $\mathrm{L}_{\mathrm{D}}=0.7 \mathrm{~nm}$. The $\varepsilon_{0}$ is the dielectric permittivity of a vacuum.

\section{Results}

\section{Neuronal Analysis}

The final MultilayerPerceptron model correctly relates $89 \%$ instances (cross-validation 10) with the considered classes of evidence for impact on immunity when they are characterized by the variants of mutation, the time of first detection, total charge change, and charge change in chosen S1/S2 area. Charge change in RBD may be omitted. Fitted parameters fall in the range, for the weights, -1.99 to 2.19 , and the threshold, from -2.95 to 1.41 .

Changing area of interest $\mathrm{S} 1 / \mathrm{S} 2$ for $\mathrm{RBD}$, or both areas, decrease correctness of decisions to $86 \%$. Leaving a single attribute, the charge change in $\mathrm{S} 1 / \mathrm{S} 2$ cleavage area offers $82 \%$, which is more than $79 \%$, for the mutations or the time of the first detection, and $75 \%$, for the total charge change or the charge change in RBD. Other tested algorithms offer less correctly classified instances, maximum 79\% - Logistic, and 54\% - D14jMlpClassifier.

\section{Potential Energy}

The results of the calculation are presented in Figure 6.

\section{Discussion}

There is a wealth of publications showing structural data on how mutations in the SARS-CoV-2 spike protein affect the 


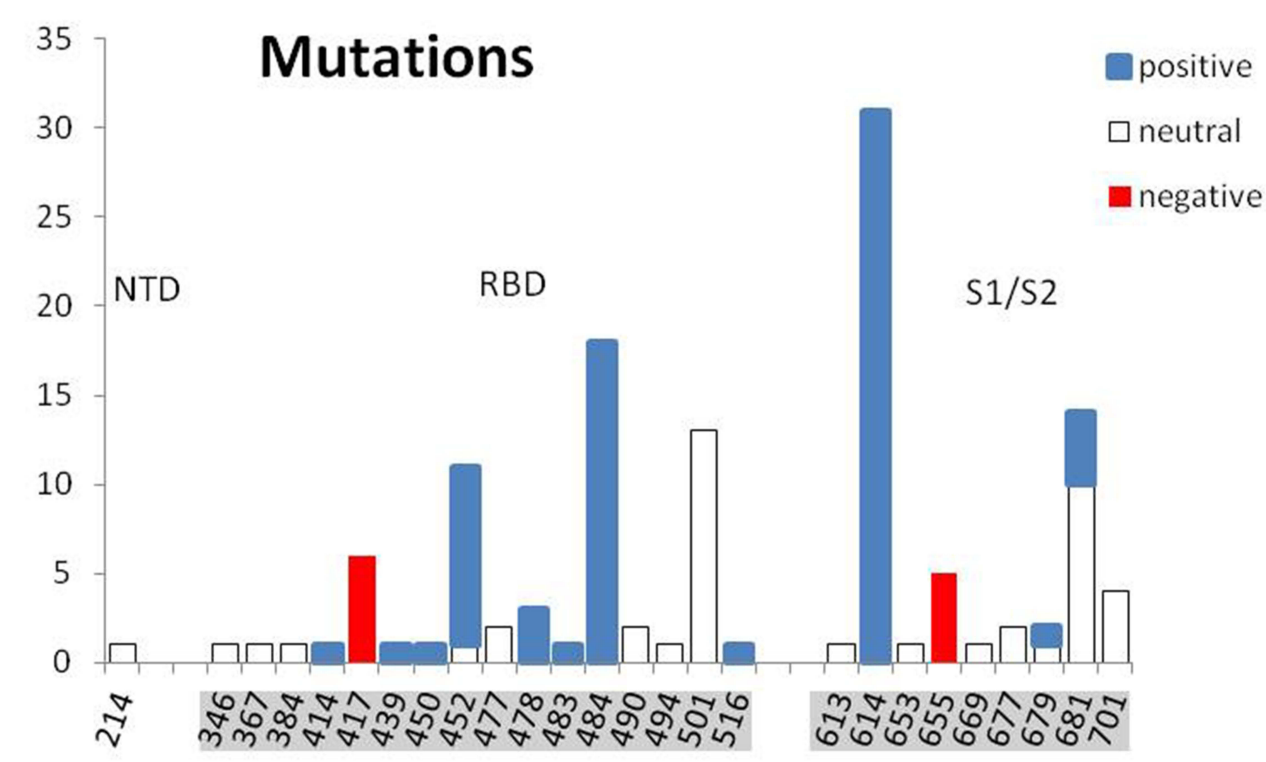

Figure 3 The distribution of reported by ECDC 32 mutations (I26 cases in 34 lineages). Mutations and the formal charge change are listed in Table I.

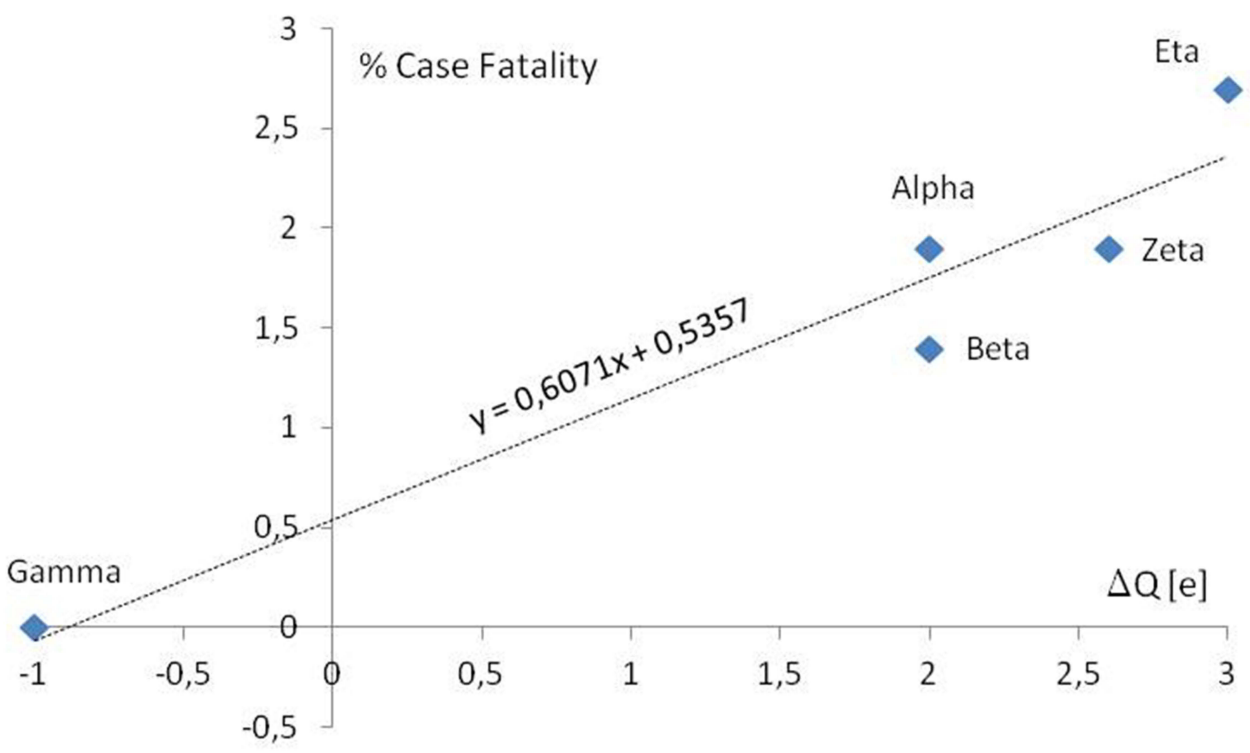

Figure 4 The COVID-19 percentage case fatality vs formal charge changes in RBD and SI/S2 cleavage regions according to PHE. In the case of WHO labeled variants, Alpha and Zeta the mean change of the charge were calculated for 2 and 5 lineages. Only well-documented variants first detected in the UK, South Africa, Japan ex Brazil, and Brazil were presented. According to the Public Health England (PHE). ${ }^{\prime \prime}$

spike structure, the interaction with the receptor ACE2, and infectivity in pseudovirus or authentic virus systems. Structural changes are crucial for PDB crystallographic predictions. However, they seem to be less important than long-range electrostatic interactions in vivo, at the distance of a few nanometers, when the virus approaches the host cell in the mucus environment.

A data report (Figures 2 and 3) indicating accumulation of amino acids carrying formally positive electrical charge in crucial areas of spike S protein, in new variants of SARS-
$\mathrm{CoV}-2$, raises the question about its impact on immunity. The shortage of data (Figure 4) may raise some doubts about the broadcasting of the importance of this phenomenon. However, neuronal analysis (Figure 5) of the S charge impact on immunity shows that this question is worth an answer. Variant Delta of the virus has raised the charge +2 both in the RBD and $\mathrm{S} 1 / \mathrm{S} 2$ cleavage areas. According to the MultilayerPerceptron classifier model, the change in the S1/S2 cleavage area seems to be more important. It is probably due to the strengthening of the interaction of spike residuals with negatively charged furin. ${ }^{13}$ 


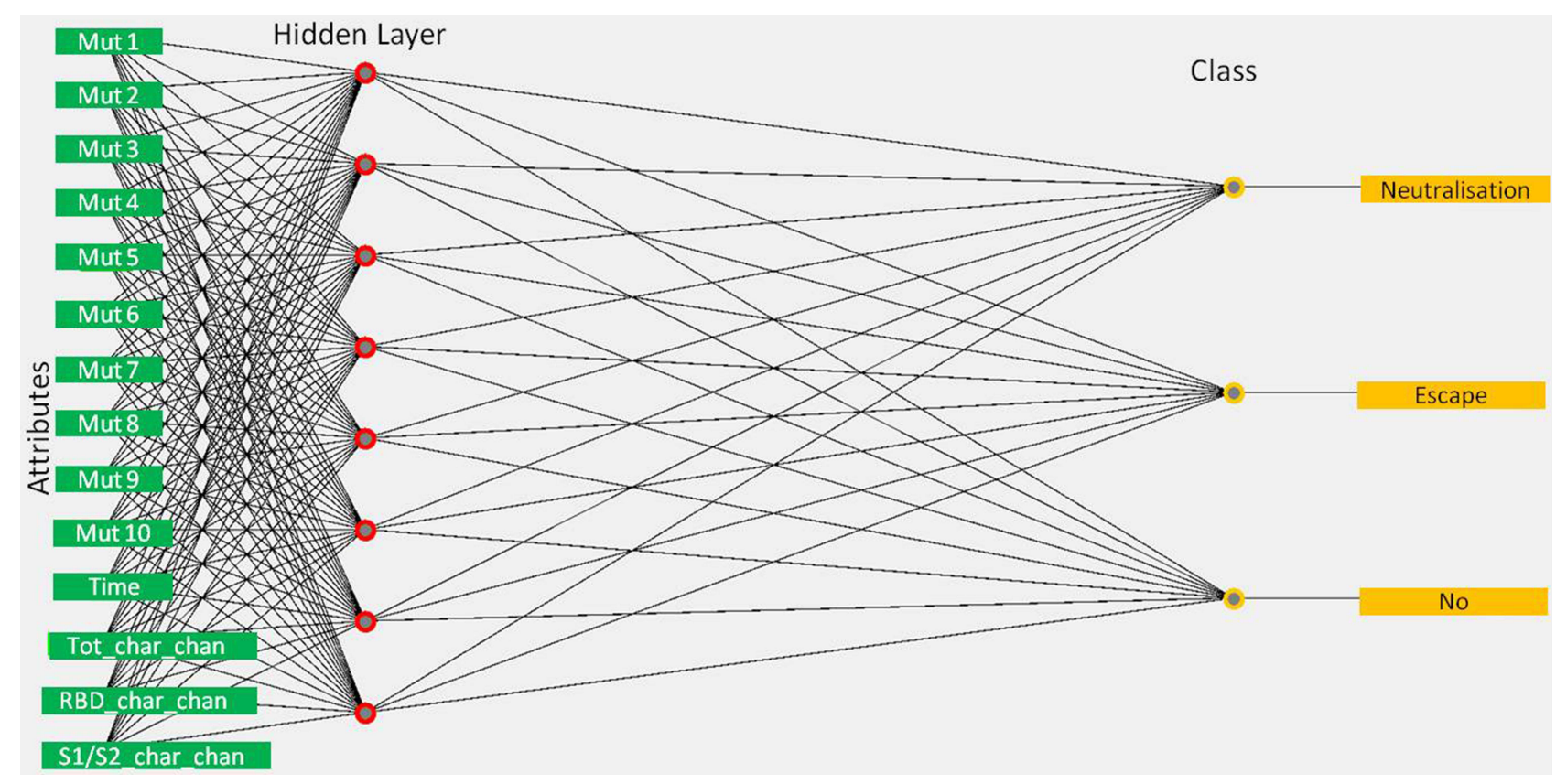

Figure 5 Conceptual visualization of the final model built using Weka 3.8.5 MultilayerPerceptron classifier for decision making, relating attributes of virus lineages to the evidence for impact on immunity \{no, neutralization, escape\}. For simplicity only selected 10 mutations are shown in the input layer of neuronal networks. Circles represent neurons and lines represent synapses. The model contains the input layer of considered attributes (32 mutations, time of the first detection, the total change of charge in S, the charge change in RBD, and the charge change in the SI/S2 cleavage area), one hidden layer to process the classification decision, and the output layer of classes for impact on immunity. Synapses take the input and multiply it by a fitted weight. Neurons add the outputs from all synapses and apply a sigmoid transfer function with a fitted threshold.

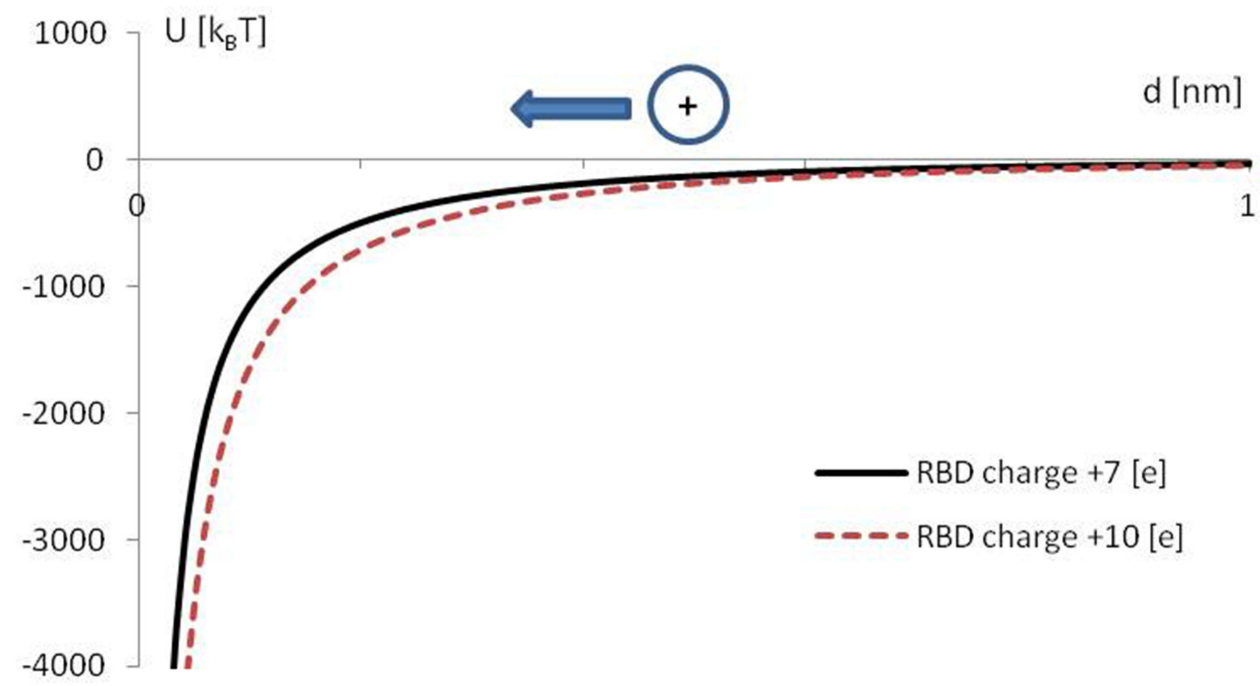

Figure 6 The potential electrostatic screened energy $U$ is estimated for charged RBD and ACE2 as a function of a distance $d$. Point model and screened Coulomb energy $\mathrm{U}=\mathrm{Q}_{1} \mathrm{Q}_{2} \operatorname{Exp}\left(-\mathrm{d} / \mathrm{L}_{\mathrm{D}}\right) /\left(4 \Pi \varepsilon_{0} \varepsilon \mathrm{d}\right)$ was assumed, with $\mathrm{Q}_{1}=+7[\mathrm{e}]$ or $\mathrm{Q}_{1}=+10[\mathrm{e}], \mathrm{Q}_{2}=-28\left[\mathrm{e}\right.$, $\varepsilon=80$, and Debye screening length $\mathrm{L}_{\mathrm{D}}=0.7 \mathrm{~nm}$. The $\varepsilon_{0}$ is the dielectric permittivity of a vacuum. Two curves represent different RBD charges, referential (+7 [e]) and after positive charge mutation (+I0 [e]), as in virus variant Zeta A.VI. The arrow indicates the direction of attraction of the positive electric charge.

The change of the total charge or the charge in RBD is also important for discussing classification, but less than supported with mutations and the time of the first detection. This reminds us that the force of electrostatic attraction between the positive RBD and the negative ACE2 (Figure 6), is an important but not the only factor. The distributions of charged amino acids in RBD and the time of epidemic development may be significant, too. Furthermore, each positive increase of virus surface charge, especially near the epitopic sites, can decrease the effectiveness of positively charged antibodies. ${ }^{14}$ This requires 
further investigations of the virus proteins ${ }^{15}$ and the soft matter physicochemical interactions ${ }^{16}$ preceding drugs implementation. The author realizes that this analysis and finding are too presumptive and need data support from the wet lab. Some experimental support for the idea of the essentiality in virus infectivity, the mutations increasing the number of positive residues comes from the work on negatively charged polysulfates binding to the spike protein via electrostatic interactions. ${ }^{17}$ Although the isoelectric point of the spike glycoprotein, $\mathrm{pI}=6.24,{ }^{18}$ is less than physiological, $\mathrm{ph}=7$, so the stalk part of the spike is negatively charged, ${ }^{19}$ the top part of the spike molecule, especially the $\mathrm{RBD}$, remains positively charged for a broad range of $\mathrm{pH}$. Such a charge distribution promotes the spike corona stability and enhances the virion attachment to receptors and surfaces, mostly negatively charged, ${ }^{20}$ eg, gangliosides-rich lipid rafts. ${ }^{21}$

Summing up, it seems reasonable to conclude that additional charges may implicate three important consequences:

1. The increase of the long-range electrostatic interactions of positive parts of SARS-CoV-2 with the negatively charged receptor ACE2 on the surface of the host cells.

2. The increase of the interaction of the region $\mathrm{S} 1 / \mathrm{S} 2$ with negatively charged furin enzyme catalyzing protein $\mathrm{S}$ cleavage. Inhibition of the action of positively charged antibodies.

3. Inhibition of the action of positively charged antibodies

The above can seriously enhance the toxicity of the virus.

\section{Disclosure}

The authors report no conflicts of interest in this work.

\section{References}

1. Saad-Roy CM, Arinaminpathy N, Wingreen NS, Levin SA, Akey JM, Grenfell BT. Implications of localized charge for human influenza A H1N1 hemagglutinin evolution: insights from deep mutational scans. PLoS Comput Biol. 2020;16(6):e1007892. doi:10.1371/journal. pcbi. 1007892

2. Kobayashi Y, Suzuki Y. Compensatory evolution of net-charge in influenza a virus hemagglutinin. PLoS One. 2012;7(7):e40422. doi:10.1371/journal.pone.0040422

3. Hagbom M, Nordgren J, Nybom R, et al. Ionizing air affects influenza virus infectivity and prevents airborne-transmission. Sci Rep. 2015;5:11431. doi:10.1038/srep11431

4. Li W. Structurally Observed Electrostatic Features of the COVID-19 Coronavirus-Related Experimental Structures Inside Protein Data Bank: A Brief Update. Preprints.org; 2020. doi:10.20944/preprints202003.0081.v1.
5. Pawłowski PH. Charged amino acids may promote coronavirus SARS-CoV-2 fusion with the host cell. AIMS Biophys. 2021;8 (1):111-120. doi:10.3934/biophy.2021008

6. López-Vallejo F, Martínez-Mayorga K. Furin inhibitors: importance of the positive formal charge and beyond. Bioorg Med Chem. 2012;20(14):4462-4471. PMID: 22682919. doi:10.1016/j. bmc.2012.05.029

7. Corrêa Giron C, Laaksonen A, Barroso da Silva FL. On the interactions of the receptor-binding domain of SARS-CoV-1 and SARS-CoV-2 spike proteins with monoclonal antibodies and the receptor ACE2. Virus Res. 2020;285:198021. doi:10.1016/j. virusres.2020.198021

8. Javidpour L, Božič A, Naji A, Podgornik R. Electrostatic interactions between the SARS-CoV-2 virus and a charged electret fibre. Soft Matter. 2021;17:4296-4303.

9. Luisetto M, Tarro G, Edbey K, et al. Coronavirus COVID-19 surface properties: electrical charges status. Int J Clin Microbiol Biochem Technol. 2021;4:016-027.

10. European Centre for Disease Prevention and Control. Available from: https://www.ecdc.europa.eu/en/covid-19/variants-concern. Accessed November 17, 2021.

11. Public Health England. Available from: https://assets.publishing.ser vice.gov.uk/government/uploads/system/uploads/attachment_data/ file/993879/Variants_of_Concern_VOC_Technical_Briefing_15.pdf. Accessed November 17, 2021.

12. Frank E, Hall MA, Witten IH. The WEKA Workbench. Online Appendix for Data Mining: Practical Machine Learning Tools and Techniques. 4th ed. Morgan Kaufmann; 2016.

13. Hasan A, Paray BA, Hussain A, et al. A review on the cleavage priming of the spike protein on coronavirus by angiotensin-converting enzyme-2 and furin. J Biomol Struct Dyn. 2021;39(8):3025-3033. doi:10.1080/07391102.2020.1754293

14. Wang M, Zhu D, Zhu J, Nussinov R, Ma B. Local and global anatomy of antibody-protein antigen recognition. $J$ Mol Recognit. 2018;31(5):e2693. doi:10.1002/jmr.2693

15. Huang Y, Yang C, Xu X, et al. Structural and functional properties of SARS-CoV-2 spike protein: potential antivirus drug development for COVID-19. Acta Pharmacol Sin. 2020;41:1141-1149. doi:10.1038/ s41401-020-0485-4

16. AG Cherstvy, Petrov EP. Modeling DNA condensation on freestanding cationic lipid membranes. February 2014. Phys Chem Chem Phys. 2020;16. doi:10.1039/C3CP53433B.

17. Nie C, Pouyan P, Lauster D, et al. Polysulfates Block SARS-CoV-2 Uptake through Electrostatic Interactions. Angew Chem Int Ed. 2021;60:15870.

18. Scheller C, Krebs F, Minkner R, Astner I, Gil-Moles M, Wätzig H. Physicochemical properties of SARS-CoV-2 for drug targeting, virus inactivation and attenuation, vaccine formulation and quality control. Electrophoresis. 2020;41:1137-1151. doi:10.1002/elps.202000121

19. Javidpour L, Božič A, Naji A, Podgornik R. Electrostatic interactions between the SARS-CoV-2 virus and a charged electret fibre. Soft Matter. 2021;17(16):4296-4303. PMID: 33908595 doi:10.1039/ d1sm00232e.

20. Adamczyk Z, Batys P, Barbasz J. SARS-CoV-2 virion physicochemical characteristics pertinent to abiotic substrate attachment. Curr Opin Colloid Interface Sci. 2021;55:101466. doi:10.1016/j. cocis.2021.101466

21. Fantini J, Yahi N, Azzaz F, Chahinian H. Structural dynamics of SARS-CoV-2 variants: a health monitoring strategy for anticipating Covid-19 outbreaks. J Infect. 2021;83(2):197-206. doi:10.1016/j. jinf.2021.06.001 


\section{Publish your work in this journal}

Infection and Drug Resistance is an international, peer-reviewed openaccess journal that focuses on the optimal treatment of infection (bacterial, fungal and viral) and the development and institution of preventive strategies to minimize the development and spread of resistance. The journal is specifically concerned with the epidemiology of

Submit your manuscript here: https://www.dovepress.com/infection-and-drug-resistance-journa| antibiotic resistance and the mechanisms of resistance development and diffusion in both hospitals and the community. The manuscript management system is completely online and includes a very quick and fair peerreview system, which is all easy to use. Visit http://www.dovepress.com/ testimonials.php to read real quotes from published authors. 